\title{
Global Satisfaction with Sex Life Subordinate Domain
}

National Cancer Institute

\section{Source}

National Cancer Institute. Global Satisfaction with Sex Life Subordinate Domain. NCI

Thesaurus. Code C131155.

The collection of PROMIS item scales that assess self-reported perceptions of overall sexual satisfaction in men and women. 